\title{
A Four-Stage Factor Analytic Approach to Studying Behavioral Domains
}

\author{
John Hattie \\ University of New England
}

Four stages in factor analyzing behavioral domains are outlined using a measure of mental wellbeing or seif-actualization, the Personal Orientation Inventory (POI), as an example. The stages are (1) exploratory analysis to assess the number of factors; (2) developing viable factor names that are based on theoretical arguments and ensuring that each factor consists of subscales that many researchers agree appropriately load on the factor; (3) assessing the goodness of fit using confirmatory factor analysis; and (4) cross-validating the hypothesis on new data sets. After such an analysis it is claimed that the latent structure of the POI relates to the factors Sensitivity to Self and to Others, Perception of Reality, Acceptance of Present Self, and Strongly Principled Yet Flexible When Confronting Others.

The purpose of this article is to suggest that there are four stages in a factor analytic study and that a clearer understanding of the latent structure of behavior domains should occur if these stages are followed. The four stages involve

1. Exploratory analyses to investigate dimensionality;

2. Developing factor names recognizable by other researchers that are consistent with theoretical work and the exploratory runs;

APPLIED PSYCHOLOGICAL MEASUREMENT

Vol. 5, No. 1, Winter 1981. pp. 77-88

(c) Copyright 1981 Applied Psychological Measurement Inc.
3. Simple cross-validation using confirmatory factor analysis on many data sets that represent the various types of samples;

4. Double cross-validation on different samples than those used in Steps 1 and 3.

The four stages are developed in the context of an example using the Personal Orientation Inventory.

The Personal Orientation Inventory (POI) was developed by Shostrom $(1966,1972)$ and purports to measure various aspects of mental wellbeing or self-actualization. The instrument consists of 150 pairs of alternative value judgments selected by psychotherapists over a 5-year period. There are 2 major scales and 10 subsidiary scales. Of these 12 scales only 2 are independent: The 10 subscales consist of a reshuffling of the items in the two independent scales and, in some cases, display a large degree of overlap with each other. Beginning with the 2 major scales, the 12 scales are described as

Inner directed (I: 127 items): assesses independence, self-supportedness, and whether a person is guided by internal principles rather than external influences.

Time Competence ( $T c: 23$ items): assesses the ability to tie the past and the future to the present in meaningful continuity. 
Self-Actualizing (SAV: 26 items): a high score suggests that the individual holds and lives by the values of self-actualizing people, and a low score suggests the rejection of these values.

Existentiality (Ex: 32 items): complementing the SAV scale, the existentiality scale measures flexibility in applying such SAV values or principles to one's life.

Feeling Reactivity (Fr: 23 items): a high score measures sensitivity to one's own needs and feelings.

Spontaneity ( $S: 18$ items): measures the ability to express feelings in spontaneous action.

Self-Regard (Sr: 16 items): measures the ability to like one's self because of one's strength or worth as a person.

Self-Acceptance ( $\mathrm{Sa}: 26$ items): assesses affirmation or acceptance of self in spite of weaknesses or deficiencies.

Nature of Man (Nc: 16 items): a high score means that one sees man as essentially good. The high scorer can resolve the goodness-evil, masculine-feminine, selfishness-unselfishness and spirituality-sensuality dichotomies in the nature of man.

Snyergy (Sy: 9 items): assesses the ability to see opposites of life as meaningfully related rather than as antagonistic. The synergistic person can transcend dichotomies.

Acceptance of Aggression (A: 25 items): a high score measures the ability to accept anger or aggression within one's self as natural, and the high scorer does not deny having such feelings.

Capacity for Intimate Contact ( $C: 28$ items): measures ability to develop contactful intimate relationships with other human beings, unencumbered by expectations and obligations.

The latter 10 scales are paired: SAV and Ex measure the degree to which one's values are like those of self-actualized people; $F r$ and $S$ measure sensitivity to need and feelings within one's self; $\mathrm{Sr}$ and $\mathrm{Sa}$ reflect the general area of self perception; Nc and Sy complement each other in measuring awareness; and $\mathrm{A}$ and $\mathrm{C}$ are expressions of good interpersonal contacts and reflect interpersonal sensitivity.

\section{Previous Research on the POI}

There have been many attempts to delineate the latent structure of the POI. The studies, however, have been beset with two important problems. First, principal components a nalysis has been used in all published studies. The purpose of components analysis is to condense the test scores by expressing them in terms of a relatively small number of linear independent components, whereas the purpose of factor analysis is to discover the underlying functional unities that operate to produce the test performance and eventually to describe the individual differences in terms of these distinguishable functions (see Korth, 1975; Thurstone, 1947). Further, with principal components analysis there is the problem of selecting the number of factors and the arbitrariness of choosing rotation procedures. Unrestricted and confirmatory factor analysis methods that can test the fit for the number of factors and test the fit for the patterned solution are more appropriate methods (see McDonald, 1969, 1978).

A second problem relates to item overlap, as there are a number of items which are scored on more than one scale (see Silverstein \& Fisher, 1968,1972 ). The results of any factor analysis involving such overlaps can have two interpretations: (1) that intercorrelations are spuriously high and the resultant factor structure is "built in" due to such spuriousness; or (2) that overlap is legitimate because the scales were not intended to be orthogonal. Regarding the first interpretation, Shure and Rogers (1965) analyzed the correlations based solely on the number of overlapping items of the Minnesota Multiphasic Inventory (MMPI) and found what they called neurotic and psychotic factors. Defending the MMPI, Anderson and Bashaw (1966) argued 
that the items that overlapped were a rough measure of similarity between two latent variables. Concerning the POI, Silverstein and Fisher $(1968,1972)$ also claimed that item overlap resulted in a built-in factor structure, giving a false impression of consistency. The second interpretation is that overlap is legitimate because the scales were not intended to be orthogonal.

All these researchers have appealed to Guilford's (1952) article "When Not to Factor Analyze" and, it seems, have missed an important statement: "In so far as the items measure factors in common to the two scores [item overlap] is legitimate." For example, if it is assumed that the behavior domain of psychiatric behavior and the behavior domain of neurotic behavior are defined, yet are not necessarily independent, then it is feasible to draw out similar items that sample both domains. There will be items, of course, that differentiate between the two domains, yet the similar items can add stability to the measurement of the domains. It may not be possible to adequately measure the behavior of a psychotic person without sampling his/her neurotic behavior also, and it may be possible to obtain a reliable indication of psychosis by asking items that also relate to neurotic behavior. Shostrom (1973) stated that in the logical development of the scoring categories the scales were not conceptualized as independent dimensions.

Silverstein and Fisher (1968) found a median item overlap correlation on the POI of only .10 and claimed that correcting for item overlap had virtually no effect on the resulting factor structure. Anderson and Bashaw (1966) used canonical correlations between obtained corrected-foroverlap scores on the MMPI; and the resulting factor structures indicated that the overlap correlations had virtually no effect on the obtained structure. Knapp and Fitzgerald (1973) used 9 POI scales based on an unreferenced "series of criterion and item factor analytic studies" that had no item overlap and found high correlations between these "purified" scales and Shostrom's (1972) 12 scales.
It seems that item overlap in the POI may not be a serious problem. A further method of assessing the importance of item overlap is to assess the goodness of fit of the matrix of correlations based on the number of overlapping items for a hypothesized pattern of factor loadings.

There have been studies that have attempted to induce patterns from factor loadings. Silverstein and Fisher $(1968,1972)$ used principal components on three correlation matrices and retained three components. The first loaded on inner directedness, feeling reactivity, acceptance of aggression, existentiality and spontaneity; the second component had high loadings on self-actualization, nature of man, and synergy; and the third, on inner directedness, self-acceptance, and time competence. No attempt at interpretation was made. Tosi and Hoffman (1972) also used principal components and found three components they called extroversion (A, S, Fr, I, C, Sr), open mindedness (Nc, Tc, SAV, Sy), and existential nonconformity (Ex, Sa, C).

Lorr and Knapp (1974), using a sample of 300 , carried out a principal components analysis on the 150 items. They found 15 components with eigenvalues greater than 1 but could only interpret 10 . They claimed that there were two subsets: (1) positive mental health and (2) a value or conception of the desirable. They found that only 70 items made up the 15 components and argued for a reduction in the number of items in the original inventory. This redundancy was also reported by Knapp and Fitzgerald (1973), Tosi and Lindamood (1975), Klavetter and Morgan (1967), and Tosi and Hoffman (1972). Starrett (1976) and Damm (1969) both proposed methods to reduce the number of items and scales.

Unfortunately, as in most 'factor analytic' studies, the researchers stopped after making comments about the principal components solution. It is thus not known whether the factor names are accurate or generalizable: One persons' interpretation of which tests load on each factor may be quite different from another's interpretation-even given the same factor names. 


\section{Stage 1: Exploratory Factor Analysis}

The aim of this study was to investigate the factor structure of the POI by using exploratory and confirmatory factor analysis. Eleven data sets which were sufficiently reported were used (see Table 1 for details).

The first hypothesis related to the number of factors. Using unrestricted common factor analysis (COFA; see McDonald \& Leong, 1974) the hypothesis was tested that there were $K$ common factors, where $K=3$ to 4 (Table 2). A first-order factor analysis model was used, $\mathbf{C}=\mathbf{H S H}^{\prime}+\mathbf{U}^{2}$. This model assumes the unique factors (U) are mutually uncorrelated and that each common factor $(\mathbf{H})$ is uncorrelated with each unique factor. Employing a maximum likelihood method with convergence set at .005 , the minimum value of the function $F$ times the $(N-1)$ is distributed approximately as the chi-square distribution with degrees of freedom: $d f=(N V-N F)^{2}-$ $(N V+N F) / 2$. For all except the Silverstein data, there was a significant improvement in the goodness of fit with four rather than three factors. (Improvement is calculated by subtracting the $\chi^{2}$ under the hypotheses that there are three factors from the $\chi^{2}$ hypothesizing four factors and using the change in degrees of freedom to assess significance.) At $\alpha=.001$, the hypothesis that there are four factors in six data sets could not be rejected. It was thus decided that a pattern based on four factors would form the basis for a confirmatory solution.

It is customary to conclude a factor analytic study after inducing some meaning from exploratory analyses such as those above. Yet such procedures can be misleading if much importance is placed on salient loadings, especially if the standard errors of those loadings are ignored. Generating theory without attempts at confirmation is certainly not a hallmark of good scientific methods. The exploratory analyses merely suggest the number of factors on which the latter confirmatory analyses are based; naming those factors should be primarily related to theoretical issues and complemented by checking that prospective factor patterns are not clearly inconsistent with the exploratory analyses. It can be misleading to dwell too much on the exploratory analyses, and it is suggested the emphasis be placed on the results of the confirmatory analyses.

It is for these reasons that little space has been allocated to detailing the results of the exploratory analyses. Such detail is still conjecture, and effort can more profitably be spent on identifying factors from the literature that will be subject to confirmatory factor analysis. It is noted that both varimax and promax rotations were used on the exploratory unrotated matrix, and the four factors to be suggested below were clearly observable. There were also many other scales loading with each factor, but the loadings either were not replicable or were theoretically inconsistent with the factor names. An analysis run on only one data set could have led to a misleading interpretation of the latent structure that would not have been replicated.

It is not clear why the Wise and Davis (1975) data sets are so dissimilar. Certainly the four- (or five-) factor pattern is similar to the other sets, and any factors beyond the fourth make little theoretical sense.

A second-order unrestricted maximum likelihood factor analysis was run using the correlations between the four primary factors specifying one factor (see right column in Table 2). In nine data sets it was not possible to reject the hypothesis that there was one factor $(\alpha=.001)$. It thus seems that there is a unidimensional construct underlying the major factors of the POI.

\section{Stage 2: Naming the factors}

A search of the literature on self-actualization was carried out to determine four factors that made theoretical sense and that were not inconsistent with the exploratory runs. After four factors were compiled, the four factor names and a description of the 12 POI tests were given to 25 staff and graduate students of the Centre 


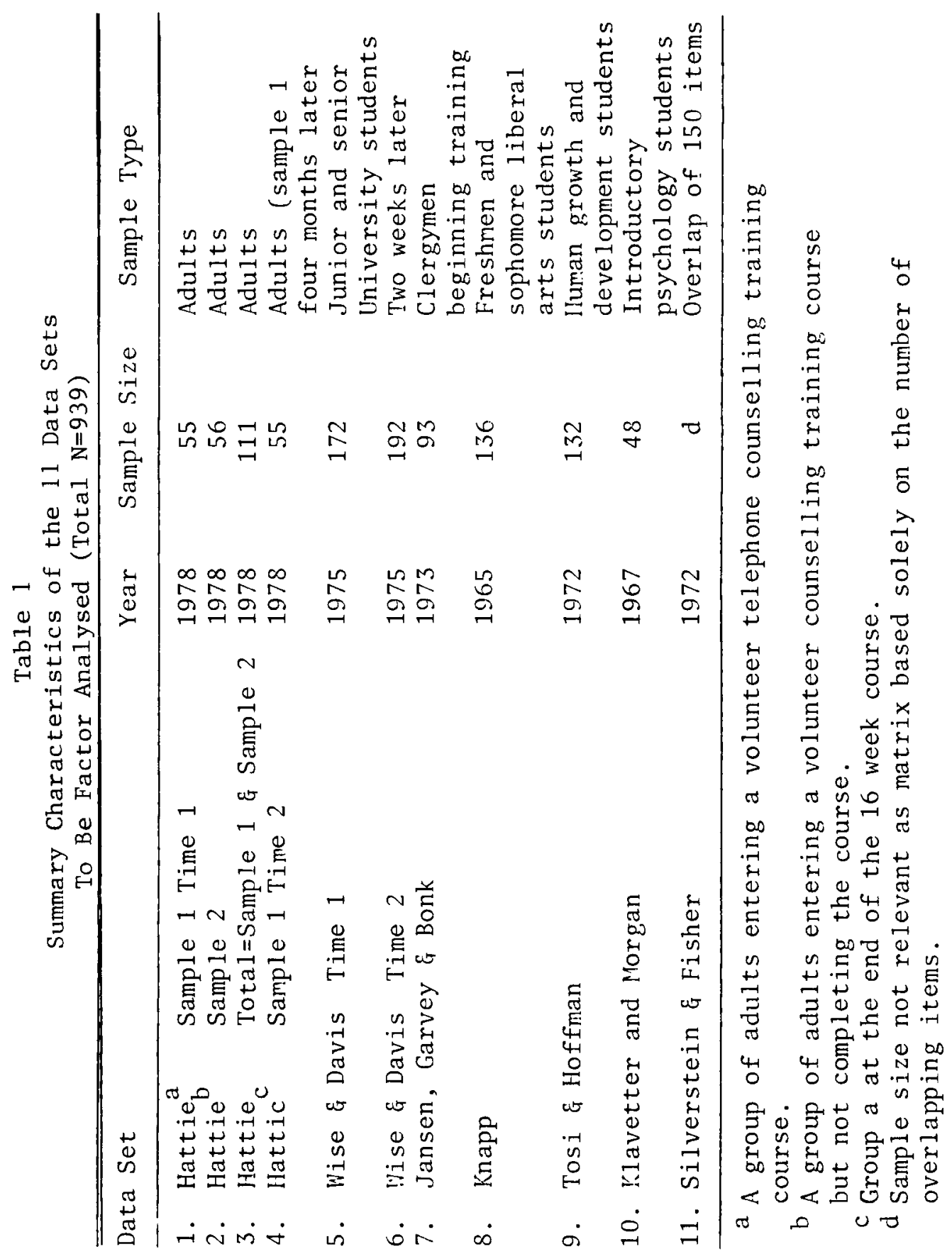


Table 2

COFA Results for Testing the Hypothesis that there are

$\mathrm{K}$ Common Factors Underlying the POI ( $\mathrm{K}=3$ to 4$)$ and Results from a Second Order Factor Analysis

\begin{tabular}{|c|c|c|c|c|c|c|}
\hline \multirow[t]{2}{*}{ Data Set } & \multicolumn{2}{|c|}{$\begin{array}{r}3 \text { factor } \\
(\mathrm{df}=33) \\
\end{array}$} & \multicolumn{2}{|c|}{$\begin{array}{c}4 \text { factor } \\
(\mathrm{d} f=33)\end{array}$} & \multicolumn{2}{|c|}{$\begin{array}{l}\text { Second order } \\
1 \text { factor } \\
(\mathrm{df}=2) \\
\end{array}$} \\
\hline & $x^{2}$ & $z$ & $x^{2}$ & $z$ & $\overline{x^{2}}$ & $z$ \\
\hline 1 & 61.98 & 2.93 & 43.98 & 2.42 & 2.00 & 1.00 \\
\hline 2 & 61.07 & 2.86 & 32.23 & 1.29 & 3.28 & 1.56 \\
\hline 3 & 105.12 & 5.84 & 66.21 & 4.28 & 0.41 & -0.09 \\
\hline 4 & 71.46 & 3.66 & 49.02 & 2.89 & 0.23 & -0.32 \\
\hline 5 & 191.46 & 9.79 & 138.58 & 8.35 & 7.02 & 2.75 \\
\hline 6 & 353.12 & 14.75 & 168.33 & 9.60 & 1.33 & 0.63 \\
\hline 7 & 68.35 & 3.43 & 41.64 & 2.19 & 11.78 & 3.85 \\
\hline 8 & 99.62 & 5.51 & 56.68 & 3.54 & 20.95 & 5.47 \\
\hline 9 & 141.15 & 7.68 & 91.00 & 5.91 & 30.87 & 6.86 \\
\hline 10 & 63.33 & 3.04 & 37.91 & 1.82 & 5.44 & 2.30 \\
\hline 11 & $19.71^{\mathrm{a}}$ & 0.39 & 8.88 & -0.34 & 3.13 & 1.50 \\
\hline
\end{tabular}

${ }^{a}$ Only the 10 subscales were used as the total matrix (12x12) was not positive definite. Hence $\mathrm{df}=18$ and 11 , respectively.

for Behavioural Studies in Education, University of New England. These people were asked to read the factor names and suggest which POI scales should load on them. This step was undertaken to counter the frequent (and often justified) criticism that naming factors is often a tautological exercise (see also Meehl, Lykken, Schofield, \& Tellegen, 1971, for an alternative method for reducing the subjective element in factor naming).

There was a remarkable consistency in the way the subtests were assigned to the factors. Discrepancies between assignments were resolved in most part by consultation with those who wrote the "deviate" classification. The following are short descriptions of the four factors and the subtests that are expected to load on the factors.

Factor 1. Sensitivity to Self and Others (I, Fr, S, $A, C)$. An underlying theme in Maslow's writing is that self-actualized people are sensitive to themselves and to others. Self-actualized people "have for human beings in general a deep feeling of identification, sympathy, and affection in spite of the occasional anger, impatience or disgust" (Maslow, 1954, p. 217). This factor is identical to Silverstein and Fisher's (1968) "affective" factor, Tosi and Hoffman's (1972) extraversion factor, and Lorr and Knapp's (1974) value factor.

Factor 2. Perception of Reality (Ex, Nc, Sy). The three subtests all relate to the ability to transcend dichotomies and suggest an ability to perceive what is there rather than to an individual's own wishes, hopes, personal theories, or to principles of the prevailing cultural group. This factor is related to Silverstein and Fisher's intellectual or conceptual phenomena, and Lorr and Knapp's (1974) acceptance of differences and positive view of human nature dimensions.

Factor 3. Acceptance of Present Self (I, Tc, $S A V, S r, S a)$. A self-actualized person could be sensitive to him/herself without accepting that self. For example, some of the 16 separate personalities of Sybil (Schreiber, 
1973) knew of other selves that made up this unique "split personality," but Sybil had difficulty in accepting those selves. Lorr and Knapp's (1974) factors of self-esteem and obligation to self seem similar to this third factor.

Factor 4. Strongly Principled Yet Flexible When Confronting Others (Tc, I, SAV, Sr. vs. Ex, $C)$. On the one hand, this fourth factor is the most difficult to document, but on the other hand, it is probably the most interesting and important factor. A person may have a perception of reality, an acceptance of him/herself, and a sensitivity to him/herself, yet may not be a self-actualized or a self-actualizing person. For example, Hitler, Attila the Hun, and Richard Nixon may have many of the attributes associated with the first three factors, yet we would be reluctant to say these people were self-actualized. There seems to be another dimension to discriminate self-actualizing from "normal" persons.

Maslow (1954) claims that self-actualized people do not feel guilty, ashamed, anxious, or defensive about such traits as laziness, thoughtlessness, loss of temper, prejudice, or shortcomings of the culture or of the group with which they have identified. Yet, the self-actualized person recognizes that the world of people in which they live may not necessarily understand or accept their code of ethics, their detachment, their spontaneity, their acceptance of self, and so forth, and since self-actualized people have no wish to hurt others or to fight with them over every triviality, they will go through ceremonies and rituals of convention with a good-humored shrug and with the best possible grace (Maslow, 1954, p. 209). But on other occasions, they can display hostile reactions to others and can be seen as oold, snobbish, and lacking in affection. Hence, there is a factor called Strongly Principled Yet Flexible When Confronting Others. This factor is related to Lorr and Knapp's (1974) adherence to principles and Tosi and Hoffman's (1972) existential non- conformity factors. If this factor is supported by the data, then contrary to the claim of Oakland, Freed, Lovekin, David, and Camilleri (1978), the POI does reflect some of Maslow's fine distinctions between appropriate and inappropriate (or realistic and unrealistic) forms of guilt, spontaneity, nonconformity, disregard for others, and the expression of hostility.

Thus, the nature of the four factors based on theoretical considerations has been hypothesized; but before this hypothesis is tested, there are four implications that should be stated. Three of the factors do retain Shostrom's groupings. Factor 1 could be rewritten as containing inner directed, feeling, and interpersonal sensitivity; Factor 2, awareness and existentiality; and Factor 3, as inner directed, time competence, self-perception, and self-actualizing. Secondly, the four factors are not expected to be orthogonal. As mentioned above, Shostrom (1973) contended that in the logical development of the scoring categories, the subscales were not conceptualized as representing independent dimensions. One consequence of Shostrom's claim was that items overlapped in more than one scale. Silverstein and Fisher's (1972) item-overlap correlation matrix was included in the present study to assess the fit of the hypothesized latent structure based only on the overlap items. Thirdly, it should be noted that the inner-directed scale consists of 127 items and loads on three factors. This is consistent with Maslow's claim that "one of the characteristics of self-actualized people, which to a certain extent crosscuts much of what we have already described is their relative independence of the physical and social environment" (Maslow, 1954, p. 213). Finally, neither the POI nor the four hypothesized factors attempted to cover all aspects of Maslow's theory. Shostrom claims that he is interested in self-actualizing people whereas Maslow studied self-actualized people. Unfortunately, a correlation matrix based on a group of self-actualized persons was not available to be included in this study. 


\section{Stage 3: Confirmatory Factor Analysis}

The goodness of fit of the four hypothesized factors was studied by confirmatory factor analysis, which was used to test hypotheses about the latent structure underlying the set of tests (see Hattie, 1979; McDonald, 1978; Mulaik, 1975, for more details). The above hypotheses were tested using McDonald and Leong's (1975) maximum likelihood confirmatory factor analysis which provides a chi-square test of goodness of fit. For ease of presentation the chisquares can be transformed to a standard normal deviate $(z>3.29$ to be significant at $\alpha=$ .001). Mulaik (1975) contends that with large samples it is very easy for trivial effects to inflate the chi-square value and argues that the residual matrix should be carefully inspected for patterns and/or large values. Bishop, Fienberg, and Holland (1975) advise that to compare several values of chi-square, $\chi^{2}$ should be divided by the sample size, thus yielding what they term a closeness index.

Moreover, if the hypothesized factor structure is accepted, this does not mean that the factor structure is necessarily "correct" but rather than it is the "best" fit. Hence, even if the factor pattern proposed can not be accepted, provided the residuals are unpatterned and small, it can be claimed that the hypothesis is the "best" in lieu of competing models.

The summary statistics are presented in Table 3. It can be seen that the four hypothesized factors resulted in good fit to the data. No residual matrix seemed patterned; the mean diagonal residual was .009 and the mean off-diagonal residual was .020 . Generally, the older the mean age of the sample, the better the fit. The average factor loadings, uniquenesses, and correlations between the four factors over the 11 samples are presented in Table 4. All loadings are reasonably large and are consistent in pattern and direction with the four hypothesized factors. The congruence coefficients calculated by the Bartlett least squares procedure between the factors across the 11 solutions are presented in Table 5; these data indicate that the factors are stable and replicable across the different dat a sets. The fourth factor is much weaker than the other three factors.

\section{Stage 4: Double Cross-Validation}

The hypotheses were cross-validated on at least 11 data sets, yet it is desirable that a fourth

Table 3

Summary Statistics Relating to the Hypothesized Factor Pattern $(\mathrm{d} f=41)$

\begin{tabular}{|c|c|c|c|c|c|}
\hline Data Set & $x^{2}$ & $z$ & $\begin{array}{l}\text { Diagonal } \\
\text { Residua1s }\end{array}$ & $\begin{array}{l}\text { Off Diag. } \\
\text { Residuals }\end{array}$ & $x^{2} / N$ \\
\hline 1 & 72.87 & 3.07 & 0.01 & 0.07 & 1.33 \\
\hline 2 & 85.37 & 4.07 & 0.00 & 0.07 & 1.52 \\
\hline 3 & 106.38 & 5.59 & 0.01 & 0.05 & 0.96 \\
\hline 4 & 75.75 & 3.31 & 0.03 & 0.07 & 1.38 \\
\hline 5 & 202.86 & 11.14 & 0.01 & 0.07 & 1.18 \\
\hline 6 & 279.92 & 14.66 & 0.00 & 0.04 & 1.46 \\
\hline 7 & 90.13 & 4.43 & 0.00 & 0.04 & 0.97 \\
\hline 8 & 137.09 & 7.56 & 0.01 & 0.06 & 1.01 \\
\hline 9 & 151.72 & 8.42 & 0.02 & 0.06 & 1.15 \\
\hline 10 & 83.30 & 3.91 & 0.02 & 0.07 & 0.74 \\
\hline 11 & 68.40 & 2.70 & 0.00 & 0.05 & 0.46 \\
\hline
\end{tabular}


Table 4

Average Factor Loadings, Uniqueness and Correlations Between the Factors over the 11 Samples

\begin{tabular}{|c|c|c|c|c|c|}
\hline \multirow[b]{2}{*}{ Scale } & \multicolumn{5}{|c|}{ Factor } \\
\hline & I & I I & I I I & IV & $\mathrm{U}^{2}$ \\
\hline$\overline{\mathrm{TC}}$ & 0 & 0 & 0.53 & 0.18 & 0.52 \\
\hline I & 0.38 & 0 & 0.82 & 0.27 & 0.11 \\
\hline SAV & 0 & 0 & 0.83 & 1.09 & 0.17 \\
\hline $\mathrm{Ex}$ & 0 & 0.98 & 0 & -0.78 & 0.12 \\
\hline $\mathrm{Fr}$ & 0.80 & 0 & 0 & 0 & 0.14 \\
\hline S & 0.73 & 0 & 0 & 0 & 0.22 \\
\hline $\mathrm{Sr}$ & 0 & 0 & 0.73 & 0.52 & 0.39 \\
\hline $\mathrm{Sa}$ & 0 & 0 & 0.77 & 0 & 0.18 \\
\hline $\mathrm{Nc}$ & 0 & 0.59 & 0 & 0 & 0.42 \\
\hline Sy & 0 & 0.60 & 0 & 0 & 0.41 \\
\hline$A$ & 0.72 & 0 & 0 & 0 & 0.24 \\
\hline $\mathrm{C}$ & 0.64 & 0 & 0 & 0.16 & 0.17 \\
\hline \multicolumn{6}{|c|}{ Correlations } \\
\hline 1 & 1 & & & & \\
\hline 2 & 0.56 & 1 & & & \\
\hline 3 & 0.67 & 0.52 & 1 & & \\
\hline 4 & -0.08 & 0.45 & -0.30 & 1 & \\
\hline
\end{tabular}

step, double cross-validation be carried out. Mosteller and Tukey $(1968,1977)$ differentiate between simple and double cross-validation in terms of the source of the samples. Simple crossvalidation occurs when the factor analysis is tested on data different from those used to choose its numerical coefficients (Step 3 above). Double cross-validation occurs when the factor analysis is tested on data different both from those used to guide the choice of its pattern and from those used to choose its numerical coeffi- cients. They suggest that fresh data be gathered after choosing the patterns and coefficients; otherwise, an iterative changing of hypothesized loadings could occur. The recent work of Saris, de Pijper, and Zegwaart (1978), suggesting numerical algorithms to find the most "confirmable" solution, illustrates how confirmatory factor analysis can be manipulated.

The data used came from a study to assess the effects of a self-actualizing program in a highschool setting (Hancock, 1980). Groups of stu-

Table 5

Average Congruence Coefficients Between the Four Factors Across the Data Sets

\begin{tabular}{|c|c|c|c|c|}
\hline Factor & 1 & 2 & 3 & 4 \\
\hline 1 & 0.85 & 0 & 0.15 & 0.06 \\
\hline 2 & 0 & 0.91 & 0 & -0.35 \\
\hline 3 & 0.13 & 0 & 0.82 & 0.40 \\
\hline 4 & 0 & -0.28 & 0.46 & 0.60 \\
\hline
\end{tabular}


dents from 11 schools were administered the POI before the program, after the program, and in a follow-up after 3 months. Only the data from the first testing was used in this study. The subsequent correlation matrices were tested using the pattern in Table 4 by confirmatory factor analysis. The results are presented in Table 6.

The fit was very satisfactory. No residual matrix was patterned, no diagonal residual was greater than in the previous 11 data sets, and only 2 off-diagonal residuals were marginally greater. The mean closeness index was 1.343 , which compares favorably with 1.269 from Table 3. The average factor loadings, uniqueness, and correlations between the factors are reported in Table 7 and it closely resembles Table 4. All the diagonal congruence coefficients between the loadings in Table 4 and 6 are greater than .98 , and the average absolute off-diagonal coefficient was .207. The average congruence coefficients between the 11 cross-validation samples were large (Table 8). Factor 4, which was weaker in congruence in the earlier analysis, is much stronger in the double cross-validation samples. Generally, it appears that there is evidence that the factor structure is replicable and is validated across many samples.

\section{Conclusions}

This paper has suggested that there are at least four steps that must be taken before arriving at viable hypotheses about the underlying latent structure of an inventory of personal orientation: (1) exploratory analyses of many disparate sets of data; (2) checking that factor labels are not mere tautologies or vague generalities existing only in the author's mind; (3) confirmatory analysis; and (4) double cross-validation. These stages were illustrated using data from the Personal Orientation Inventory.

In lieu of a more viable set of hypotheses, it can be claimed that the latent structure underlying the Personal Orientation Inventory relates to

1. Sensitivity to self and others:

2. Perception of reality;

3. Acceptance of present self; and

4. Strongly principled yet flexible when confronting others.

It is hoped that the challenge has now been made to other researchers to derive other theoret-

Table 6

Sumnary Statistics Relating to the Hypothesized Factor Pattern on the Double Cross-Validation Sample $(\mathrm{df}=41)$

\begin{tabular}{|c|c|c|c|c|c|c|c|}
\hline & Data Set & $\mathrm{N}$ & $x^{2}$ & $z$ & $\begin{array}{l}\text { Diagonal } \\
\text { Residuals }\end{array}$ & $\begin{array}{l}\text { Off Diag. } \\
\text { Residuals }\end{array}$ & $x^{2} / N$ \\
\hline 1 . & Sutherland & 75 & 51.92 & 1.19 & .01 & .08 & 0.69 \\
\hline 2 . & Albury & 34 & 63.38 & 2.26 & .01 & .07 & 1.86 \\
\hline 3 . & Waverly & 143 & 154.13 & 8.56 & .00 & .06 & 1.08 \\
\hline 4. & Wahroonga & 104 & 136.33 & 7.51 & .00 & .06 & 1.31 \\
\hline 5 . & Manly & 63 & 86.21 & 4.13 & .00 & .07 & 1.37 \\
\hline 6. & Strathfield & 135 & 177.01 & 9.82 & .02 & .08 & 1.31 \\
\hline 7. & Goulburn & 64 & 80.52 & 3.69 & .01 & .05 & 1.26 \\
\hline 8 . & Wollongong & 65 & 69.23 & 2.77 & .00 & .06 & 1.07 \\
\hline 9. & Penrith & 78 & 118.04 & 6.36 & .00 & .06 & 1.51 \\
\hline 10 . & Wagga & 116 & 170.78 & 9.48 & .00 & .06 & 1.47 \\
\hline 11. & Chat swood & 58 & 109.89 & 5.83 & .00 & .09 & 1.89 \\
\hline
\end{tabular}


Table 7

Average Factor Loadings, Uniqueness and Correlations between the Factors over the 11 Double Cross-validation Samples

\begin{tabular}{|c|c|c|c|c|c|}
\hline \multirow[b]{2}{*}{ Scales } & \multicolumn{5}{|c|}{ Factors } \\
\hline & I & I I & I I I & IV & $\mathrm{U}^{2}$ \\
\hline$\overline{\mathrm{TC}}$ & 0 & $\overline{0}$ & 0.63 & 0.27 & 0.56 \\
\hline I & 0.41 & 0 & 0.94 & 0.45 & 0.01 \\
\hline SAV & 0 & 0 & 1.17 & 1.43 & 0.06 \\
\hline Ex & 0 & 1.16 & 0 & -1.15 & 0.09 \\
\hline $\mathrm{Fr}$ & 0.72 & 0 & 0 & 0 & 0.25 \\
\hline $\mathrm{S}$ & 0.71 & 0 & 0 & 0 & 0.25 \\
\hline $\mathrm{Sr}$ & 0 & 0 & 0.86 & 0.78 & 0.34 \\
\hline $\mathrm{Sa}$ & 0 & 0 & 0.83 & 0 & 0.18 \\
\hline $\mathrm{Nc}$ & 0 & 0.55 & 0 & 0 & 0.48 \\
\hline Sy & 0 & 0.74 & 0 & 0 & 0.21 \\
\hline$A$ & 0.69 & 0 & 0 & 0 & 0.28 \\
\hline $\mathrm{C}$ & 0.80 & 0 & 0 & -0.55 & 0.12 \\
\hline \multicolumn{6}{|c|}{ Correlations } \\
\hline 1 & 1 & & & & \\
\hline 2 & 0.58 & 1 & & & \\
\hline 3 & 0.62 & 0.30 & 1 & & \\
\hline 4 & 0.04 & 0.43 & -0.48 & 1 & \\
\hline
\end{tabular}

ical models which can be tested. It is believed that such testing of alternative hypotheses will help users become more aware of the behavior domain to which they are generalizing.

\section{References}

Anderson, H. E., \& Bashaw, W. C. Further comments on the internal structure of the MMPI. Psychological Bulletin, 1966, 66, 211-213.

Bishop, Y. M. M., Fienberg, S. E., \& Holland, P. W. Discrete multivariate analysis: Theory and practice. Cambridge, MA: MIT Press, 1975.
Damm, V. J. Overall measures of self-actualization derived from the Personal Orientation Inventory. Educational and Psychological Measurement, 1969, 29, 977-981.

Guilford, J. P. When not to factor analyze. Psychological Bulletin, 1952, 49, 29-37.

Hancock, P. Growth in self-actualisation after a highschool retreat programme. Unpublished master's thesis, University of New England, Armidale, Australia, 1980.

Hattie, J. A. The Progressive Achievement Tests: A confirmatory factor analysis. New Zealand Journal of Educational Studies, 1979, 15, 172-187.

Table 8

Average Congruence Coefficients Between the Four Factors Across the 11 Double Cross-validation Data Sets

\begin{tabular}{|c|c|c|c|c|}
\hline Factor & 1 & 2 & 3 & 4 \\
\hline 1 & 0.94 & 0 & 0.12 & -0.07 \\
\hline 2 & 0 & 0.87 & 0 & -0.33 \\
\hline 3 & 0.08 & 0 & 0.77 & 0.45 \\
\hline 4 & -0.08 & -0.35 & 0.52 & 0.84 \\
\hline
\end{tabular}


Klavetter, R. E., \& Morgan, R. E. Stability and internal consistency of a measure of self-actualization. Psychological Reports, 1967, 21, 422-424.

Knapp, R. R., \& Fitzgerald, O. R. Comparative validity of the logically developed versus "purified" research scales for the Personal Orientation Inventory. Educational and Psychological Measurement, 1973, 33, 971-976.

Korth, B. Exploratory factor analysis. In D. J. Amick \& H. J. Walberg (Eds.), Introductory multivariate analysis. Berkeley, CA: McCutchen, 1975.

Lorr, M., \& Knapp, R. R. Analysis of a self actualization scale: The Personal Orientation Inventory. Journal of Clinical Psychology, 1974, 30, 355-357.

Maslow, A. H. Motivation and personality. New York: Harper, 1954.

Meehl, P. E., Lykken, D. T., Schofield, W., \& Tellegen, A. Recaptured item technique (RIT): A method for reducing somewhat the subjective element in factor naming. Journal of Experimental Research in Personality, 1971, 5, 171-190.

McDonald, R. P. A generalized common factor analysis based on residual covariance matrices of prescribed structure. British Journal of Mathematical and Statistical Psychology, 1969, 22, 149-163.

McDonald, R. P. A simple comprehensive model for the analysis of covariance structures. British Journal of Mathematical and Statistical Psychology. 1978, 31, 59-72.

McDonald, R. P., \& Leong, K. S. Common factor analysis (COFA). A FORTRAN computer programme. Toronto, Ontario Institute for Studies in Education, 1974.

McDonald, R. P., \& Leong, K. S. Covariance structures analysis (COSA). A FORTRAN computer programme. Toronto, Ontario Institute for Studies in Education, 1975.

Mosteller, F., \& Tukey, J. W. Data analysis, including statistics. In G. Lindzey \& E. Aronson (Eds.). The handbook of social psychology (2nd ed.). Reading, MA: Addison-Wesley, 1968.

Mosteller, F., \& Tukey, J. W. Data analysis and regression. Reading, MA: Addison-Wesley, 1977.

Mulaik, S. Confirmatory factor analysis. In D. J. Amick \& H. J. Walberg (Eds.), Introductory multivariate analysis. Berkeley, CA: McCutchen, 1975.

Oakland, J. A., Freed, F., Lovekin, A., Davis, J. P., \& Camilleri, R. A critique of Shostrom's Personal Orientation Inventory.Journal of Humanistic Psychology, 1978, 8, 75-85.

Saris, W. E., de Pijper, W. M., \& Zegwaart, P. Detection of specification errors in linear structural equation models. In K. F. Schuessler (Ed.), Sociological methodology, 1979. San Francisco: JosseyBass, 1978.

Schreiber, F. R. Sybil. New York: Penguin, 1973.

Shostrom, E. L. Personal Orientation Inventory: An inventory for the measurement of self-actualiza. tion. California: Edits, 1966, 1972.

Shostrom, E. L. Comments on a test review: The Personal Orientation Inventory. Journal of Counseling Psychology, 1973, 20, 479-481.

Shure, G. H., \& Rogers, M. S. Note of caution on the factor analysis of the MMPI. Psychological Bulletin, 1965, 63, 14-18.

Silverstein, A. B., \& Fisher, G. Is item overlap responsible for a "built-in" factor structure? Psychological Reports, 1968, 23, 935-938.

Silverstein, A. B., \& Fisher, G. Item overlap and the "built-in" factor structure of the Personal Orientation Inventory. Psychological Reports, 1972, 31, 492-494.

Starrett, R. H. Modifications of the Personal Orientation Inventory for improved specific trait predictions. Journal of Consulting and Clinical Psychology, 1976, 44, 676-677.

Thurstone, L. L. Multiple factor analysis: A development and expansion of the vectors of the mind. Chicago: University of Chicago Press, 1947.

Tosi, D. J., \& Hoffman, S. A factor analysis of the Personal Orientation Inventory. Journal of Humanistic Psychology, 1972, 12, 86-92.

Tosi, D. J., \& Lindamood, C. A. The measurement of self-actualization: A critical review of the Personal Orientation Inventory. Journal of Personality Assessment, 1975, 39, 215-224.

Wise, G. W., \& Davis, J. E. The Personal Orientation Inventory: Internal consistency, stability, and sex differences. Psychological Reports, 1975, 36, 847-855.

\section{Acknowledgments}

I am grateful to Dale Burnett and Don Fitzgerald for their helpful improvements and to Peter Hancock for supplying cross-validation data.

\section{Author's Address}

Send requests for reprints or further information to John Hattie, Centre for Behavioural Studies, University of New England, Armidale, N.S.W. 2351, AUSTRALIA. 